\title{
The Impact of Climate Change on The Beginning of Wet Season
}

\author{
Rr. Rintis Hadiani ${ }^{1}$, Susilowati ${ }^{2}$, A.P. Saido ${ }^{3}$, Setiono $^{4}$ \\ 1,2,3,4 (Civil Engineering, University of Sebelas Maret, Surakarta, Indonesia)
}

\begin{abstract}
The Impact of Climate Change on the Start of Wet Season Climate Change is the change in the start of the wet and dry season. The start of the wet season is to be marked with a cumulative of 2 month rainfall. It will be different in each catchment area. This number is often used as a benchmark of planting time. That is why the beginning of the wet season known as the beginning of planting time. If planting start can be predicted, then it may be some adaptation on cropping patterns.

The aim of research is to find the climate change based on characteristic of historical data, and then predict the start of wet and dry season on the next time series period.The method is the model predictionof Artificial Neural Network Back Propagation. The results showed that the initial season was shifted 2 weeks until 6 weeks. This study concluded that climate change causes changes to the monsoon in the next 6 years. The impact of climate Change in the start of the wet season is the start of planting time. The reliability model is $80 \%$.
\end{abstract}

Keyword: Climate Change, wet season.

\section{Introduction}

In the short term, the aim is to predict the wet season and planting season to determine the discharge is available during the planting season. Climatic conditions can greatly affect on planting conditions ([5]).

The science has been developing rapidly within the last decade, especially the Hydrological Sciences. If hydrological science is followed by the use of technology, there will be very meaningful or itself and the development of technology as well. The hydrological science can be used and applied easily in daily life ([1]; [7]).

In this research, it is called the start of the wet season when rainfall occurs 2 consecutive months with certain cumulative. The value of cumulative data on each watershed is different ([3]). The Climate change effect on the rainfall and either with the discharge in the watershed ([2]). This will affect the early occurrence of wet season ([3]).

\section{Research Method}

The method used in this research was literature review and building model based on artificial neural network. The model was verified towards a watershed area with similar characteristic (sub watershed of the Bengawan Solo River), and the model to be applied to other sub watersheds (in The Bengawan Solo watershed). The data are used in the model must be consistent. Consistency test is made by double mass curve. If the graphic is linear line, then the data time series can be said consistently. Historical data must according to the model. To determine the input data must be known in advance of data characters. The character data are determined by autocorrelation test ([3]). Analysis of lag the time series data will determine to the pattern of data inputs to the neural network ([4]).

The drought is analyzed based on calculating the water balance, by calculating the deficit condition in the watershed ([1]). Analysis of the threshold is determined based on the probability ([8]). The probability is according to the distribution function of historical rainfall data. Analysis of distribution function performed with Minitab to find normal distribution or gamma distribution ([4]). The Selected distribution is used to find the probability of rainfall $50 \%$ or $\mathrm{P}_{50}$ (median) and an average rainfall $\left(\mathrm{P}_{\text {average }}\right)([8])$.

The outliers of data are determined by statistical analysis. If there is, then this data will disrupt the pattern formed by the model ([6]). If the data has been qualified, then it will build a neural network model ([7]; [5]).

This is an inference model of with input and output data of rainfall at a certain time ([9]). The pattern of the input data is the part of character of the output data. The pattern of historical data is divided by 3 i.e.The series of input data, training data, and output data. This model is called a Back Propagation Neural Network. To find out the suitability of the character data output and data input performed statistical tests. Testing is done by calculatingcumulative density function (cdf) and probability density function (pdf) the output data. The surplus and deficit rainfall data are defined by a threshold. Based on the analysis of the run length can be seen the start of the wet season on historical data and data on the results of the simulation model. 
III. ResultAnd Discussion

The requirement of the model is consistency. Based on that requirement, a statistical test was conducted and showed that the data was consistent, so that the data was valid to be processed in the artificial neural network model. The data had 24 lags which meant the period 1 of January 2007 was influenced by the period 1 of January 2006, etc. As shown in Fig. 1.

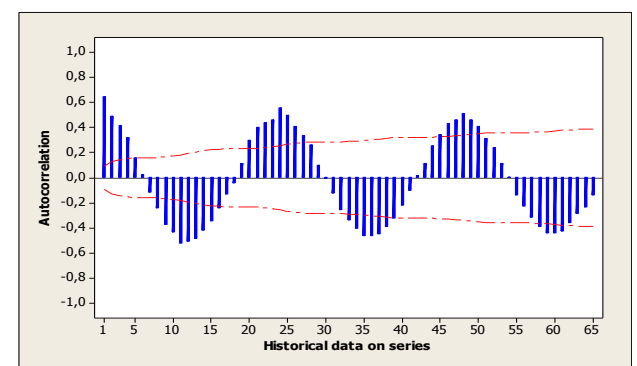

Fig. 1. Autocorrelation of rainfall data based on a 1991-2008 (with 5\% significance limits for author relations) Furthermore, it was necessary to determine the distribution, from Fig. $2 a$ and $2 b$, the AD value then to be obtained. The smallest value indicated the right distribution was gamma.

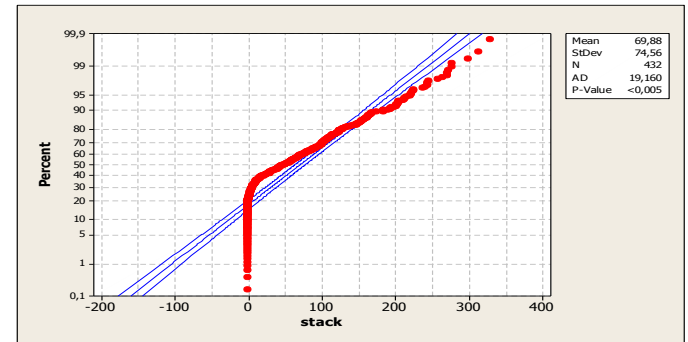

Fig. 2a. AD value of normal distribution of the historical data $(95 \% \mathrm{CI})$

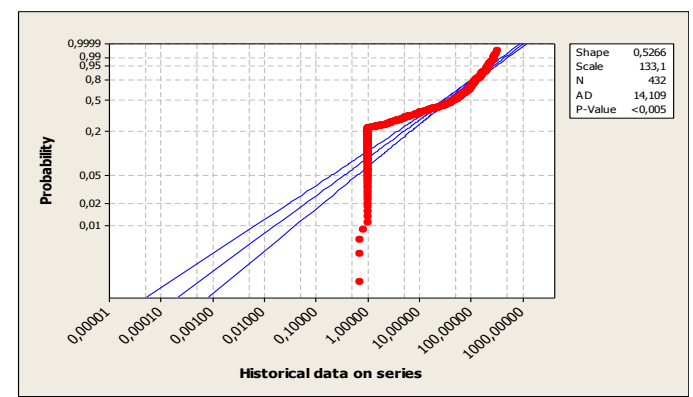

Fig. 2b. AD value of gamma distribution $(95 \% \mathrm{CI})$

Data in gamma distribution is shown in Fig. 3. The red line is a cdf function of rainfall data, and the blue one if gamma distribution functions. The historical data has a valueof median 33.3 means that a normal height of rainfall is $33.3 \mathrm{~mm}$.

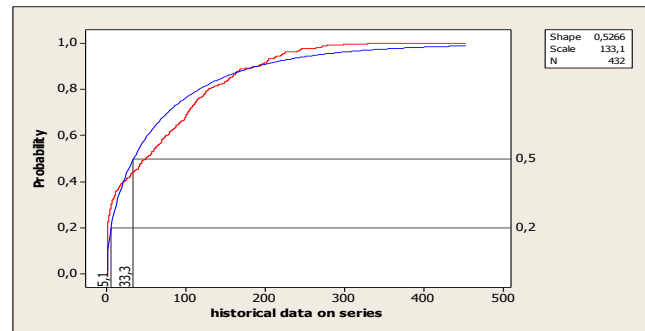

Fig. 3.Cdfof historical datafrom Gamma distribution

The dataoutliner was very distracting to the model; hence a reduction of dataoutlinerss was undertaken by replacing them with the maximum occurrence of rainfall. Mathematically, the outline is determined by a value which is greater than 1.5 by Q3-Q1 (where Q3 and Q1 are the value of quartile 75\% and 25\% respectively). Some of outlines are shown in Fig. 4. 


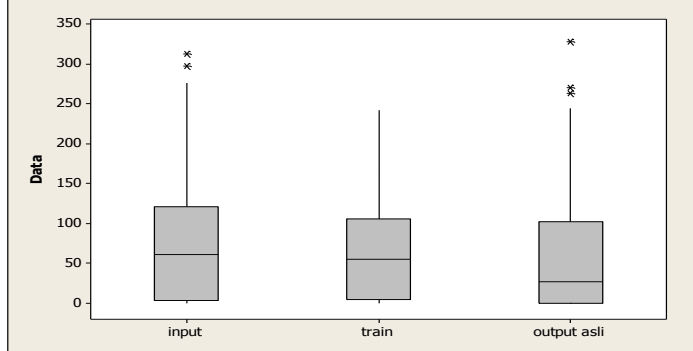

Fig. 4.Boxplot of 3 groups of historical data comprising input, training and output data.

The result of thesimulation showed that simulation data have a similar characteristicof input data, shown in Fig. 5.

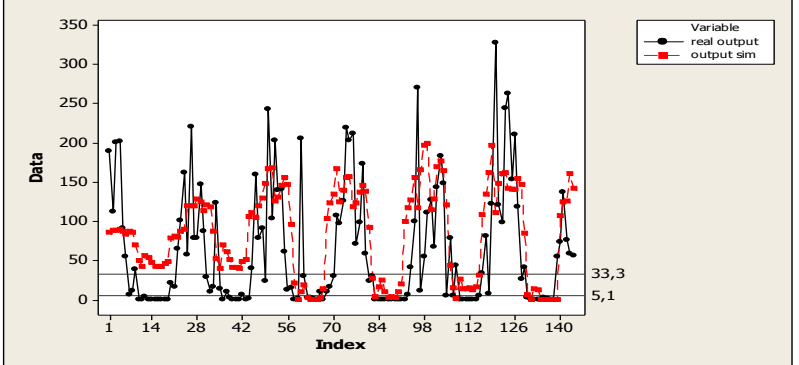

Fig. 5. Data obtained from the model (real data and simulation data)

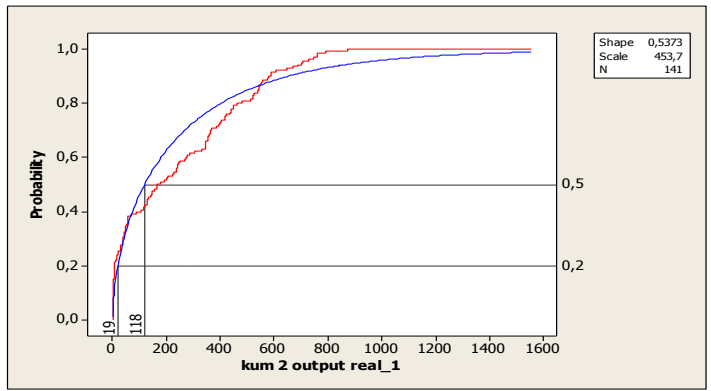

Fig. 6. Cumulative cdf of historical rainfall 2 monthly data (by Gamma distribution)

Based on the above analysis, it can be seen that a cumulative probability of 2 monthly of $\mathrm{P}_{50}$ is 118 , it means that wet season will start if rainfall cumulative reach $118 \mathrm{~mm} \sim 100 \mathrm{~mm}$. The result of analysis of historical data shows a shift in start of season as is seen in Fig. 7 and Fig. 8.

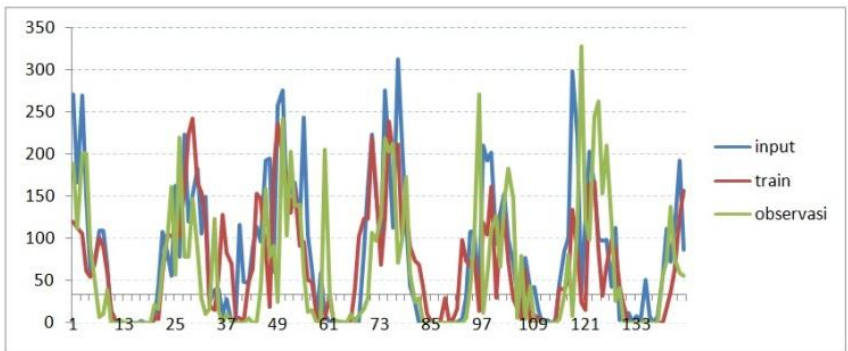

Fig. 7. The graph shifts at the start of the wet and dry season

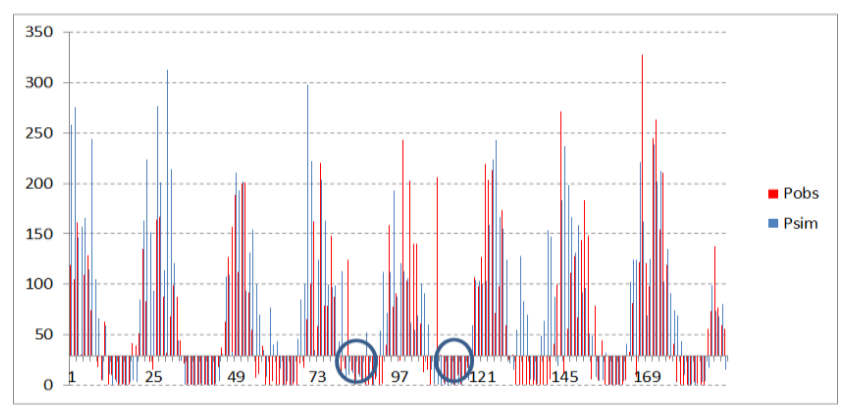

Fig. 8. Prediction of drought by model simulation 
'Pobs' is the observation data of rainfall. 'Psim' is the simulation data of rainfall. The circle shows that the data was not in the same time. It's indicated that the time of that condition were moved (wet condition).

It means that the historical data indicate the start of season shift from 2 to 4 points or one to two months. The result of prediction shows that the year 2011-2013 will be in dry. The result of the test shows thatthe model is still valid until $80 \%$.

\section{Conclusion}

The wet season will start when cumulative of 2 monthly rainfall reach $118 \mathrm{~mm} 100 \mathrm{~mm}$, bothwet and dry season in historical data shift 1-2 month backward. The result of prediction based on rainfall data show that there does not exist rainfall (little rainfall along 2011-2012)

\section{Acknowledgements}

Thank you to "Direktorat Jenderal Pendidikan Tinggi, Indonesia" for funding this research.

\section{References}

[1]. Asdak, C., HidrologidanPengelolaan Daerah Aliran Sungai. (Yogyakarta, Gadjahmada Press.,2004).

[2]. Evans, Jason P.,Modelling climate-surface hydrology interactions in data sparse areas. Australian National University (Australia, 2001), 338 pp.

[3]. Hadiani,,R.,AnalisisKeandalanMetodeAutoregresidalamMenentukanMusimTanam.Thesis. Bandung Institute of Technology, 1994

[4]. AnalisisKekeringanberdasarkan Data Hidrologi.” Doctoral diss. Bandung Institute of Technology, 2009

[5]. Kartasapoetra, Ance Ginarsih Ir, Klimatologi : Pengaruh Iklim Terhadap Tanah dan Tanaman. Bandung, 2004, Bumi Aksara.

[6]. RedaTaha,.Artificial Neural Network (ANNs) in Structural Engineering.http://www.reda_taha.com/research/ANN.htm,, 2002

[7]. Mays, LW., Water Resources Handbook. (AmerikaSerikat, McGraw-Hill. 1996)

[8]. Tallaksen, LM., Van Lannen, HAJ.,. Hydrological Drought. Process and Estimation Methods for Streamflow and Groundwater. Elsevier. UK., 2006

[9]. Turban,E.,Aronso,E., Liang, TP.,. Decision Support Systems and Intelligent Systems (SistemPendukungKeputusanDanSistemCerdas). ( Yogyakarta, PenerbitAndi, 2005). 